\title{
Que planejamento(s) orienta(m) 0 ensino da escrita na Educação Básica?
}

\section{Maria Auxilladora Bezerra}

Professora Doutora da Universidade Federal de

Campina Grande.

Resumo: O objetivo do presente trabalho é descrever e comentar planejamentos de atividades escolares com a escrita, tanto em livros didáticos quanto em aulas de português (língua materna) e em cursos de formação continuada de professores. Descrição e comentário estão baseados nos conceitos de planejamento didático, de modelo didático e no ensino da escrita desde o trabalho com a redação até com os gêneros textuais. Observase que os planos de ensino de escrita (que compõem os planejamentos), quando ocorrem, enfatizam ora a estrutura textual, ora 0 aspecto metodológico do ensino do gênero ou do texto. O modelo didático não está presente em nenhum dos dados observados.

Palavras-chave: Modelo didático; plano de atividades; apropriaçẫo de modelos
Résumé: Le but de cet article est de décrire et faire des commentaires sur des planifications d'activités scolaires sur l'écrit, qui sont présentes dans des manuels didactiques, aux cours de portugais (langue maternelle) et aux cours de formation d'enseignants. Cette déscritption et ces commentaires suivent les concepts de planification didactique et de modèle didactique et le parcours de l'enseignement de l'écrit dès la rédaction jusqu'au genre textuel. Les plans d'enseignement de l'écrit (qui composent la planification), quand il y en a, mettent en évidence soit la structure textuelle, soit l'aspect méthodologique de l'enseignement du genre ou du texte. II n'y a pas de modèle didactique dans les manuels ni dans les cours analysés.

Mots-clés : Modèle didactique ; plan d'activités ; appropriation de modèles 



\section{Introdução}

Em trabalho anterior (BEZERRA, 2006), fizemos um breve percurso histórico do ensino da produção textual escrita em língua portuguesa, nas escolas brasileiras, considerando a redação, a produção de texto e o gênero textual. Constatamos que os Parâmetros Curriculares Nacionais de língua portuguesa impulsionaram o ensino de gêneros textuais escritos, baseando-se em teorias enunciativas e discursivas.

Sabendo que um dos princípios das teorias de gênero é observá-lo em situações comunicativas de fato, percebemos que orientações pedagógicas, livros didáticos e cursos de formação de professores de língua materna recomendam o trabalho com gêneros textuais/discursivos na sala de aula, para que os alunos se apropriem desses gêneros em seus usos efetivos. Essa recomendação chega, às vezes, a ser entendida de forma extremista: todo texto escrito na sala de aula deve ter um destinatário externo à escola, deve procurar a resolução/denúncia de um problema, conter solicitação de algo, exposição de pontos de vista, ou ter caráter jornalístico, entre outros pontos. Chega-se, assim, a desviar-se de um dos objetivos da escola, que é o ensino sistematizado da escrita. Ou seja, parece que não pode haver espaço para ensinar-se a escrever, em contextos de simulação também, para que os alunos reflitam sobre o que aprendem ou sobre o que ainda não aprenderam.

Mesmo reconhecendo que cabe à escola proporcionar-lhes situações em que essa modalidade da língua seja exigida e de forma adequada, quer dizer, que haja um ensino contextualizado, não podemos desprezar o fato de que ela é objeto de ensino/aprendizagem em sala de aula. Nesse sentido, pretendemos com o presente trabalho descrever e comentar planejamentos de atividades escolares com a escrita, tanto em livros didáticos quanto em aulas de português (língua materna) e em cursos de formação continuada de professores. Para essa descrição e comentário, abordaremos os conceitos de planejamento didático, de modelo didático e o ensino da escrita desde o trabalho com a redação até com os gêneros textuais. 
${ }^{1}$ Trata-se de diversos dados colhidos ao longo de nossas pesquisas (a partir da década de 80 do século $\mathrm{XX}$ ) sobre ensino de língua materna, livros didáticos e formação do professor de português.
Este artigo está organizado em três tópicos, além desta introdução: o primeiro aborda conceitos teóricos relativos à área de planejamento didático; o segundo discorre sobre ensino do texto escrito, focalizando dados empíricos; e o terceiro contém algumas considerações nossas sobre ensino desse texto, finalizando o artigo. $\mathrm{O}$ conjunto de dados empíricos a que nos referimos provém de livros didáticos de língua portuguesa do Ensino Fundamental (atividades escolares e orientações ao professor), de planos de aulas de português e de orientações para o ensino de língua materna dadas a professores em formação continuada ${ }^{1}$.

\section{O conceito de planejamento e de modelo didático}

$\mathrm{O}$ ato de planejar sempre foi proposto aos professores e futuros professores pelas diversas instâncias envolvidas com o ensino: na escola, pelo setor pedagógico (coordenador da área de língua portuguesa, assessor pedagógico, coordenação e supervisão escolar, entre outros); nos cursos de formação, por professores de língua portuguesa, de didática, de prática de ensino, de estágio supervisionado, por exemplo. Todos procuram sistematizar o conjunto de atividades a ser desenvolvido, em um determinado espaço de tempo, tendo em vista os objetivos a serem alcançados. Assim, conforme Gil (1997), planejamento de ensino corresponde à ação do professor de selecionar o conteúdo programático para o grupo de alunos, de estabelecer os objetivos a serem atingidos, as estratégias e os recursos que vai adotar para facilitar a aprendizagem, os critérios de avaliação e a bibliografia pertinente ao conteúdo selecionado.

Considerando que todo ser humano é constituído sócio-historicamente, esse planejamento é marcado por uma perspectiva de educação, que implica valores, atitudes, crenças e modos de agir dos professores envolvidos (LIBÂNEO, 2004). Ele é processual, pois não se restringe apenas ao momento de elaboração dos planos de trabalho: é uma atividade constante de reflexão, ação 
e revisão, para possibilitar o alcance dos objetivos. Esse caráter processual não era identificado nos anos 70-80 do século passado, quando se propunha um planejamento rígido, influenciado pelo tecnicismo educacional de então. A partir do final dos anos 80 e início dos 90 , quando o binômio ensino-aprendizagem passa a ser o interesse de pesquisadores sobre educação e de educadores, as ações escolares são estudadas e/ou planejadas considerando-se o imbricamento do trabalho do professor com o do aluno.

Para a concretização do planejamento, são necessários os planos de trabalho, documentos que contêm conjuntos particulares de atividades, para orientar o desenrolar sistemático do trabalho docente. Estamos nos referindo a planos de aula, planos de curso ou outro plano que o professor possa elaborar para o desenvolvimento de seu trabalho em sala de aula.

Em relação aos planos de aula, podemos dizer que, segundo a perspectiva de educação e de ensinoaprendizagem defendida, eles focalizam tópicos variáveis: demodogeral, podemosafirmarque, na década de 70 (século $\mathrm{XX}$ ), esses planos, com o foco no ensino, primavam pelo rigor e inflexibilidade tecnicista, enfatizando os objetivos comportamentais; na década de 80 , com a divulgação da teoria construtivista e o foco na aprendizagem, os planos passaram a enfatizar a metodologia (o como propor aos alunos para construírem seus conhecimentos); na década de 90, difundindo-se as teorias sociointeracionistas e a ênfase no processo ensino-aprendizagem, esses planos tornaram-se mais flexíveis, focalizando estratégias de ensino e avaliação. Nesta primeira década do século XXI, vemos a ampla divulgação de teorias sociointeracionistas - influenciando o ensino de língua - e das teorias enunciativas e discursivas sobre a língua, que trazem para o ensino aspectos sociais e históricos do sujeito que aprende. A perspectiva de se construir os conhecimentos na interação do professor com os alunos, considerandose os mais experientes auxiliando os novos aprendizes (influência do conceito de Zona de Desenvolvimento Proximal - ZDP - de VIGOTSKY, 1984), interferiu na 
realização dos planos, não lhes sendo dada tanta atenção. Assim, professores deixaram de fazê-los. Associe-se a isso (não preparação de planos) o fato social de desvalorização profissional dos docentes (o que interfere na sua motivação) e a adoção maciça, pelas escolas, de livros didáticos de língua portuguesa, que oferecem atividades, comentários e respostas ao professor, retirando dele a tarefa de planejar seu ensino. Retira-lhe também sua voz, sua autonomia. Como afirma Rojo (2001, p.332), “o professor abriu mão de uma de suas atribuições básicas - a de ser 'dono da voz', isto é, a de planejar seu ensino de acordo com as necessidades e possibilidades de seus alunos".

Tentando-se recuperar essa atribuição, tanto nos cursosdeformaçãoinicial(quegarantemaprofissionalização dos estudantes: as licenciaturas, os cursos normais) quanto na formação continuada (aqui entendida como os estudos realizados, em concomitância com o trabalho docente, orientados por outros profissionais: cursos de pós-graduação stricto e lato sensu, formação dentro da jornada de trabalho, ações promovidas pelas Secretarias de Educação etc.), procura-se ensinar a planejar o ensino. Isso porque é da competência do professor ensinar. Em se tratando de texto escrito, cabe a ele se deter nos aspectos linguístico-textuais, enunciativos, discursivos e temáticos, para que seus alunos sejam autores dos próprios textos.

Esse procedimento se relaciona diretamente ao chamado discurso didático (MATENCIO, 2001), que se caracteriza pelo 'fazer aprender' e que ocorre no interior de um quadro institucional definido (a escola, por exemplo), pois visa transmitir conhecimentos, produzidos em diversas instâncias (não somente a científica), a um público específico, que se define em função de sua ZDP e de um nível de ensino.

Nesse sentido, recorremos ao conceito de modelo didático, proposto por Dolz, Schneuwly e De Pietro (1998), para verificar como o planejamento do ensino da escrita está sendo proposto. De Pietro e Schneuwly (2002, p.4-5) descrevem esse conceito em três dimensões: é um produto que tem uma estrutura, resulta de um processo 
de construção e é um instrumento para construção no sequências de ensino. Assim, o modelo didático é observar-s, visto que propõe uma sequência de ensino a varia, en e, mas ao mesmo tempo seu nível de elaboração mais $\mathrm{m}$ função dos gêneros a serem ensinados: gêneros dada a isados e descritos exigem modelo mais detalhado, eles. a quantidade de conhecimentos produzidos sobre eles; gêneros implícitos, conhecidos mais por intuição, têm modelo mais abrangente, dada a falta de conceitualização a seu respeito.

Comoproduto, omodelotem, essencialmente, cinco componentes: a definição geral do gênero, os parâmetros do contexto comunicativo, os conteúdos específicos, a estrutura textual global e as operações linguageiras e suas marcas linguísticas. Como construção, o modelo didático leva em conta as práticas sociais de referência, a literatura sobre gênero, as práticas linguageiras dos alunos e as práticas escolares. Como instrumento, o modelo permite construir, para um mesmo público-alvo, atividades de ensino/aprendizagem diversas e sequências de ensino/ aprendizagem de complexidade crescente, acompanhando o desenvolvimento dos aprendizes.

O modelo didático envolve, portanto, a seleção do que ensinar sobre o objeto escolhido e a adequação do ensino aos aprendizes, levando em conta o que eles já sabem a respeito do assunto e o que precisam aprender. O processo de elaborar o conjunto de atividades a serem desenvolvidas em sala de aula (ou não) entre professor e alunos, a fim de que estes últimos se apropriem de um determinado conhecimento, pode ser chamado de modelização (ROJO, 2001, p.318). Como estamos tratando da escrita de textos, a modelização envolve a caracterização do gênero a ser ensinado/aprendido (segundo as concepções teóricas adotadas), o levantamento de informações do que os alunos já sabem sobre o gênero, a comparação entre o que sabem e o que precisam saber, de acordo com sua ZDP e o nível de escolaridade em que estão e, em seguida, a preparação do conjunto de atividades que serão realizadas para que ocorra a aprendizagem 
dos alunos. Esse conjunto de atividades, ao ser posto em prática, leva em consideração o tempo e o material escolar e os objetivos de ensino estabelecidos.

Com essas informações sobre planejamento e modelo didático, passamos ao item seguinte, para descrevermos o ensino da escrita.

\section{O ensino da escrita na escola}

Ensinar a escrita sempre foi um dos objetivos da escola. Para isso, as orientações didáticas, influenciadas pelas concepções de aprendizagem e de língua/ linguagem, seguem os modelos teóricos da psicologia da aprendizagem e ora os modelos da gramática normativa, ora os da linguística. Tendo em vista que os aportes teóricos tanto da linguística quanto da psicologia se modificam, continuamente, de acordo com as pesquisas realizadas, sob pontos de vista diversos, nessas áreas do conhecimento, o ensino da modalidade escrita da língua também se altera, a partir da concepção de escrita que se adota, não havendo mais, atualmente, a exclusividade da influência da gramática normativa. Vejamos, por exemplo, o livro didático Português: uma proposta para o letramento, de Magda Soares, publicado em 2002 (1ª edição), ao propor a produção de texto ao aluno de 5 a série do Ensino Fundamental baseando-se na perspectiva enunciativa de linguagem:

Ex. 1: Recorde o título desta unidade: A família como ela é?

Depois que leu tantos textos que respondem a essa pergunta, você pode responder a esta outra pergunta:

E a sua família, como é que ela é?

1. Escreva um texto com este título: $\mathrm{E}$ a minha família, como é que ela é?

2. Escrever sobre a própria família é um assunto muito pessoal. Por isso, você pode:

- ler oralmente seu texto para a turma, se quiser que seus colegas conheçam sua família e seu texto; 
- escolher um ou alguns colegas para ler e comentar com você seu texto;

- dar seu texto só para o professor ler;

- guardar seu texto só para você - produzir este texto deve ter ajudado você a refletir sobre sua família e a entendê-la melhor.

(SOARES, M. Português: uma proposta para o letramento. São Paulo: Moderna, 2002, v.5, p.135-6)

A sugestão para escrever um texto descritivo, após o aluno ter lido vários outros (literários e não literários) e ter observado seus usos e debatido sua temática, e para divulgá-lo ou não (caso não queira, tendo em vista que se trata de assunto muito pessoal), está ancorada na concepção de língua como ação entre os indivíduos, segundo a qual os interlocutores têm o que dizer entre si e agem uns sobre os outros.

No planejamento didático dessa atividade, dirigido ao professor, a autora orienta-o a levar o aluno a refletir sobre a função da escrita, aponta o objetivo da produção do texto e sugere uma discussão sobre a atividade realizada, como podemos ver no exemplo 2:

\section{Ex.2: PRODUÇÃO DE TEXTO}

$\mathrm{Na}$ faixa etária em que se encontram os alunos, neste nível de escolaridade, são freqüentes os conflitos com a família; é, pois, adequado que (...) o aluno seja levado a refletir, por meio da escrita, sobre sua própria família (...). Ao mesmo tempo, pretende-se que este tipo de texto leve o aluno a descobrir a função catártica da escrita.

Gênero do texto: Descritivo (com possibilidade de o aluno optar por texto narrativo).

Objetivo da produção do texto: Escrever como forma de reflexão sobre temas pessoais.

Sugestão: Após a realização da atividade, discuti-la com os alunos, levando-os a reconhecer a escrita como forma de reflexão sobre a própria realidade, fazendo-os concluir que muitas vezes se escreve 
para si mesmo, e não para outros; essa função da escrita é que justifica a opção de o texto ser ou não lido por outros.

(SOARES, M. Português: uma proposta para o letramento. São Paulo: Moderna, 2002, v.5, p.135-6)

Assim, o trabalho didático com a língua considera a enunciação linguística como forma fundamental, inclusive não sendo objetivo do professor corrigir os erros linguístico-textuais, pois texto dessa natureza pode ser escrito apenas como reflexões para o próprio autor. No entanto, vale salientar que, do ponto de vista do planejamento, não há informações sobre o texto descritivo, nem como o professor poderia desenvolver suas aulas, nem em que espaço de tempo. Ou seja, parece caber ao professor fazer seu próprio planejamento, de acordo com sua realidade docente.

Retomando o tópico "gramática", visto que ela pautou o ensino de língua materna até a segunda metade do século $\mathrm{XX}$, constatamos que o ensino da escrita de textos prezava pela obediência às normas e aos modelos canônicos - e escolares - narração, descrição e dissertação. Além disso, fundamentava-se, sobretudo, na concepção de aprendizagem por estímulo-resposta. Observando materiais didáticos da década de 1960, verificamos que, sob a influência da concepção de escrita como um produto resultantedaapropriaçãode estruturaslinguístico-textuais, o ensino estava focado, efetivamente, na apropriação dos modelos pelos aprendizes. O planejamento estava voltado para a descrição da estrutura textual, observando-se textos prototípicos, havendo figuras (quadros ou pinturas) como motivação para os textos narrativos e/ou descritivos e temas abstratos, subjetivos ou sociais e econômicos, para os textos dissertativos.

Entre os anos 1960 e 1970 , era comum, no dia da aula de redação, serem apresentadas cenas urbanas ou rurais, paisagens, pessoas, para serem descritas em um texto chamado 'composição', ou, a partir dessas figuras, criarem-se narrativas. Para as dissertações, 
podiam ser dados temas, tais como: 'O pôr do sol', 'A felicidade', 'A fome', 'A crise do petróleo' (este último, muito abordado, pelo risco de extinção desse combustível). O objetivo de tais tarefas escolares era demonstrar domínio das normas gramaticais, das partes que compõem cada uma das estruturas textuais (descrição, narração e dissertação) e, no caso da dissertação, conhecimento do tema. Tendo em vista que a língua era concebida como código e a aprendizagem, como resultado de um condicionamento, o ensino da escrita, consequentemente, se processava pela repetição das normas, seguindo modelos. Acreditavase que os alunos aprendiam na escola para utilizare os conhecimentos aprendidos após terminarem os estudos, ou seja, a escola se voltava para o futuro. Os planos de aula eram elaborados pelo professor (não havia ainda o domínio do livro didático) e avaliava-se o aluno pelo que ele demonstrava ter ou não aprendido nas tarefas escolares respondidas. Em relação ao texto escrito, era da responsabilidade do aluno aprender a escrevê-lo sem erros.

Com isso, vemos que a escola procurava instrumentar seus alunos de tal forma que, ao necessitarem de escrever um texto, eles teriam modelos a seguir. $\mathrm{Ou}$ seja, havia um planejamento para o ensino da escrita, na medida em que eram selecionados os conteúdos a ser ensinados de acordo com as séries escolares (não com as necessidades socio-cognitivas dos alunos), estabelecido o objetivo (dominar as normas linguístico-textuais) e preparado o conjunto das tarefas a serem realizadas.

Considerando as coleções de livros didáticos da década de 70 (séc. XX), podemos ilustrar essa afirmação com um exemplo retirado do livro didático de Reinaldo Mathias Ferreira, Comunicação: atividades de linguagem, publicado em 1977.

Ex.3:

Para escrever a estória O Sonâmbulo, Humberto de Campos seguiu o plano que lhe mostramos. Se 
lhe dermos um plano já feito, você saberá escrever uma estória? Temos certeza de que sairá bonita e engraçada. Aqui está o plano:

\section{Título: FOI BUSCAR LÃ E SAIU TOSQUIADO}

a. Um viajante pediu pousada numa fazenda e foi recebido.

b. O fazendeiro, para se divertir, resolveu cobrirse com um lençol e assustar o hóspede.

c. O hóspede, já alertado, descobriu o plano e o pôs em prática antes do fazendeiro.

d. O fazendeiro, desprevenido, assustou-se muito.

(FERREIRA, R. M. Comunicação: atividades de linguagem. São Paulo: Ática, 1977, v.5, p.115-6)

Essa proposta de escrita pressupõe ser a língua um enunciado, um produto acabado, e para demonstrar ter o aluno aprendido a escrever um texto narrativo de suspense, ele deve atender ao que foi dado, elaborando, possivelmente, quatro parágrafos, já que foram dados momentos dessa narrativa de ficção.

Ao longo da coleção, há uma ênfase excessiva, para o ensino da redação, nos planos do texto a ser estudado e escrito. Isso nos leva a supor que o autor acredita ser a posse de um esquema de composição o único requisito para o aluno se apropriar do texto escrito.

Com a influência da linguística na produção de material escolar e na formação dos professores de português, o ensino, a partir do final dos anos 1980, passou a incorporar outras variedades de textos, refletindo outras concepções teóricas sobre língua (pragmáticas, enunciativas, discursivas), além de outras concepções sobre aprendizagem (construtivistas, interacionistas). Procurou-se ensinara escreverlevando-seem consideração condições de produção de um texto (interlocutores, objetivos, situação comunicativa). Com isso, houve, de início, um deslocamento do ensino de redação para texto (nas aulas de português buscava-se 'produzir textos', não mais 'fazer redação') e, posteriormente (já no final da 
década de 90 do século passado), outro deslocamento de 'texto' para 'gênero textual/discursivo'.

O ensino de produção textual, influenciado pela linguística de texto, enfatiza critérios de textualidade, como coesão, coerência, intertextualidade, sem descurar a norma linguística, que passa a ser considerada em segundo momento do processo de aprendizagem e de avaliação. Os planos de aula têm como objetivo do ensino possibilitar ao aluno a escrita de textos de acordo com a sua macroestrutura e adequados à situação social. Notamos, nessa tendência, uma preocupação com o ensino ora voltado para o presente, ora para o futuro, na medida em que inclui a produção de um texto direcionado para uma necessidade efetiva dos alunos e a produção de um texto que lhes propiciará condições de leitura e escritura, caso eles venham a precisar. Podemos ilustrar essa afirmação com os exemplos 4 ( $a$ e $b$ ) e 5 abaixo, retirados de uma coleção de livros da $1^{\text {a }}$ à $4^{\mathrm{a}}$ e da $5^{\mathrm{a}}$ à $8^{\mathrm{a}}$ série do Ensino Fundamental, respectivamente.

Ex.4 a: Ordenação de partes para organização de uma história

Acabe de numerar as partes na ordem certa para contar a história.

(Há uma história da literatura infantil, apresentada em partes separadas e fora de sua seqüencia, para os alunos reordená-las, seguindo dados lógicotemporais e coesivos).

(Erdna P.Nahum. Meu caderno de redação e criação.

São Paulo: Scipione, 1993, v.3, p.34-35)

Ex. 4 b:

Professor faça uma leitura em voz alta das partes da história. Depois leia o primeiro conjunto de frases e, através de questões, estimule as crianças a descobrirem a seqüência que deve completá-lo. As partes da história podem estar escritas em tiras de cartolina que serão afixadas na ordem certa no 
mural, na lousa ou na parede da sala de aula.

(Erdna P.Nahum. Meu caderno de redação e criação.

São Paulo: Scipione, 1993, v.3, p.34)

\section{Ex. 5: PRODUÇÃO}

Imagine esta reprodução (uma gravura do conde de Garves, a cavalo) ilustrando um anúncio de espetáculo circense. Sente-se com um colega e escrevam o anúncio do espetáculo.

\section{AVALIANDO}

Há o nome do circo?

O preço, a data e o horário das apresentações foram citados?

O texto está coerente com a reprodução?

(...)

As palavras estão escritas corretamente e de maneira legível?

(Ma. F. Cócco e M.A. Hailer. ALP. São Paulo: FTD, 1994, v.5, p.107)

Em (4 a) observamos que o propósito do ensino é desenvolver habilidades cognitivas dos alunos (especificamente a aprendizagem da estrutura de um texto narrativo), associando, de forma assistemática, unidades lingüísticas (pronomes, expressões temporais) a ilustrações e conteúdo do texto. Assim, enfatiza-se a organização textual, considerando-se aspectos coesivos e de coerência. Constitui-se numa proposta de trabalho com o texto que procura tornar o aluno conhecedor e produtor de narrativas.

Em relação ao planejamento para a realização dessa atividade (4 b), a autora focaliza apenas sugestões metodológicas de leitura das partes que compõem a história, para os alunos indicarem a sua sequência lógica. O ensino-aprendizagem ocorre de forma assistemática, provavelmente por intuição. 
Já em (5) a ênfase recai sobre o uso social do texto: a elaboração de um anúncio que divulgará um espetáculo de circo. Mesmo que não seja um texto a ser efetivamente divulgado, a proposta favorece o aluno a se apropriar desse modelo de texto. Notamos que as perguntas (7 ao todo) que guiam os alunos a avaliar seu texto privilegiam aspectos informativos, sendo a última dedicada à adequação linguística, mostrando que o código, mesmo estudado, não constitui o ponto de partida para a escrita e avaliação do texto. Esse posicionamento difere do trabalho com a redação, em que as normas linguísticas e estruturas composicionais constituíam o foco principal.

Não há a preocupação inicial com o código linguístico, visto que a concepção de língua/linguagem é a de ação entre os seus usuários, que se comunicam, se influenciam, argumentam, contra-argumentam, entre outros atos de fala (língua como interação); reforça-se o aspecto social da escrita. Mas é necessário que haja planejamento e elaboração de atividades escolares que sistematizem o ensino/aprendizagem da escrita em função da variedade de gêneros textuais. Para essa atividade do exemplo 5, os autores deixam a cargo do professor seu desenvolvimento.

Reconhecemos que, com a expansão do sistema escolar brasileiro, a proletarização do professor de ensino fundamental e médio e a presença decisiva do livro didático nas escolas, a prática de elaborar planos de aulas, como foi dito anteriormente, sofreu um impacto a ponto de quase desaparecer (era suficiente o planejamento geral que ocorria no início do ano letivo ou de cada semestre). Tendo em vista que esse livro passou a direcionar o ensino de língua materna, o planejamento didático é feito agora por seus autores, cabendo aos professores, praticamente, desempenhar a função de animador, ou seja, aquele que põe em funcionamento o que está previsto, com algumas modificações (se for o caso) que venham adequar a situação de ensino à sala de aula.

Podemos verificar que planos de ensino do texto escrito ora são detalhados, ora gerais, com orientações 
muito amplas. Constam informações sobre características estruturais do texto a ser redigido, orientações sobre a exploração temática e observações sobre a correção linguística. Quando o livro aborda a avaliação, o faz chamando a atenção do professor para a possibilidade de leitura do texto por outro interlocutor, que não seja o próprio professor, de revisão e reformulação, após releitura ora do próprio autor, ora de algum colega de sala, mas não encontramos orientações para o professor corrigir e avaliar o texto do aluno. O exemplo 6 , a seguir, retirado da coleção $A$ palavra é português, de Graça Proença e Regina Horta, publicada em 1996, demonstra um plano de ensino de redação sucinto e com algumas orientações para a avaliação.

Ex. 6: Propostas de redação

Procuramos propor sempre pelo menos duas redações para que o aluno escolha a que mais o interessa. A outra proposta pode ser utilizada como lição de casa. Sugerimos a troca de redações entre os alunos para que percebam que todo texto pode ter leitores. Por isso, precisa ser claro e comunicar alguma coisa.

Para a avaliação das redações, sugerimos os seguintes critérios:

a) organização do conteúdo;

b) adequação do conteúdo à proposta;

c) adequação do conteúdo à escolaridade do aluno;

d) correção gramatical (ortografia, sintaxe, pontuação);

e) vocabulário (extensão e adequação ao conteúdo). (PROENÇA, G. e HORTA, R. A palavra é português. São Paulo: Ática, 1996, v.6, p.4)

Acompanhando a atividade de redação, há no livro do professor um lembrete, retomando o primeiro parágrafo do exemplo 6 , sem abordar a avaliação nem detalhar como o professor poderia ensinar o aluno a compor um texto escrito. É o que vemos no exemplo 7: 
Professor: apresentamos duas propostas de redação para o desenvolvimento da narração em primeira pessoa. Cada aluno deve escolher a que mais the interessar. A outra pode ser aproveitada em aulas posteriores ou como exercício para casa.

(PROENÇA, G. e HORTA, R. A palavra é português. São Paulo: Ática, 1996, v.6, p.21)

O plano didático se restringe a enfatizar a aparente flexibilidade da proposta (o aluno escolhe uma das duas opções dadas, mas a não escolhida nesse primeiro momento poderá ser realizada posteriormente), os critérios de avaliação e o caráter comunicativo do texto (leitura para os colegas). Orientações mais específicas sobre o ensino de narrativa em primeira pessoa não são encontradas.

Com a influência das teorias lingüísticas enunciativas e discursivas (linguística aplicada, lingüística funcional, sociolinguística, análise de discurso e outras), já na segunda metade da década de 90, a escrita passou a ser vista como uma prática social, e seu ensino foi orientado para se basear em situações efetivas de comunicação. Esse procedimento pressupõe a aprendizagem de gêneros e suas relações com discursos e textos em circulação; a valorização da interação mediada pela escrita e de suas condições de produção; a abrangência de situações de produção de texto; e a aprendizagem dos usos linguísticos inerentes à elaboração e ao uso dos gêneros.

Assim, enfatizam-se atualmente as práticas sociais de escrita, tanto em livros didáticos, quanto na formação inicial e continuada de professores de língua materna e em aulas de português. $O$ ensino da produção de um texto, tendo como enquadramento o gênero, exige um plano de trabalho, que focaliza o que privilegiar desse gênero, para o grupo de aprendizes. Aqui, é importante esclarecer que nem sempre os textos escritos na sala de aula devem, necessariamente, ter uma função social real (e um destinatário a quem se 
envie esse texto), pois a escrita constitui um conteúdo específico de ensino, da mesma forma que as operações matemáticas são ensinadas, muitas vezes, em problemas fictícios. Enfim, o que precisamos ter claro é que a escola não pode deixar de ensinar a escrever, para se limitar a considerar os aspectos sociais de circulação dos gêneros.

Com a perspectiva de escrita como prática social, os modelos didáticos a serem desenvolvidos na sala de aula vão incluir informações sobre a circulação social dos textos, sua temática, sua composição e seus aspectos linguísticos. No entanto, tem ocorrido que livros didáticos e planos de aulas de português (quando há) não propõem modelos didáticos que orientem, efetivamente, o ensino de textos escritos, possibilitando uma progressão entre os diferentes graus de aprendizagem: há uma supervalorização do tema, a crença de que uma discussão oral desse tema favorece a elaboração de bons textos e de que a escrita se dá por um 'passe de mágica' (Rojo, op.cit.), já que não ocorre de fato o ensino. O exemplo 8, a seguir, ilustra o que foi dito.

Ex. 8: PLANO DE UNIDADE

Objetivo: atender à língua na sua função social e às dificuldades apresentadas por uma turma de $8^{\underline{a}}$ série de uma escola pública, no que se refere ao gênero textual - carta, seja ela informal ou formal.

$1^{\circ}$ momento: leitura silenciosa do texto do livro didático em uso e discussão oral (...).

$2^{\circ}$ momento: dividir a turma em equipe e distribuir textos sobre o tema em estudo (...).

3ำ momento: dividir a turma em equipes e entregarlhes exemplos dos mais variados tipos de correspondência, como o bilhete, a carta informal/formal, e-mail etc. 4o momento: Observar e transcrever os pronomes de tratamento constantes nas correspondências citadas. 
5 momento: orientação para a produção de uma carta formal dirigida ao futuro governador do estado.

(Atividades de aula planejadas por professora em curso de formação continuada, 2002)

A ênfase nesse plano de unidade é dada mais à metodologia do que ao ensino propriamente dito: fazse leitura em voz alta, discutem-se as ideias do texto, trabalha-se em equipes. Em relação ao ensino da escrita do gênero em destaque (carta), ocorre apenas a orientação para serem identificados os pronomes de tratamento, após o que será escrita uma carta formal com destinatário determinado. Ou seja, a aprendizagem da escrita desse gênero textual parece mais um exercício de inspiração, ou de mágica, sendo os pronomes de tratamento o que poderá dificultar sua elaboração, como se fosse esse elemento linguístico o que caracteriza uma carta.

Parece-nos que, por receio de parecer desatualizado ou 'fora de moda', ou por não compreender com clareza a proposta de ensino de textos escritos, professores de português não ensinam as características específicas dos gêneros, de tal modo que os alunos se apropriem delas e demonstrem fazer uso eficaz da diversidade de gêneros. Não conseguindo esse intento, muitas vezes encontramos aulas de português ou livros didáticos que se restringem a expor a estrutura dos variados gêneros textuais, a solicitar aos alunos que escrevam um semelhante, acreditando que, com isso, não trabalham com redação, nem com produção textual, mas com gêneros.

O modelo didático, proposto por Dolz, Schneuwly e De Pietro (1998), conforme abordamos nas primeiras páginas deste artigo, não é encontrado em nosso material de análise. A elaboração e execução do plano de atividades, quando ocorrem, enfatizam aspectos textuais e temáticos. Mesmo reconhecendo que o modelo didático pode ter uma força normalizadora, em consequência de suas características (produto que tem uma estrutura e é um instrumento para construção de sequências de ensino), o 
conjunto de atividades por ele previsto contribui para que o professor, efetivamente, se dedique ao ensino de gêneros, afastando-se da redação. Sem planejamento que inclua aspectos discursivos, enunciativos, temáticos, textuais e linguísticos, além dos conhecimentos sobre gênero que têm os alunos, o trabalho com a escrita constitui apenas o ensino de redação, com lacunas, pois às vezes nem a preocupação com estrutura e língua, que havia décadas atrás, ocorre.

\section{Considerações finais}

Embora defendamos a utilização de situações efetivas de escrita em sala de aula, não estamos eliminando o fato de que o texto, ao chegar aí, perde parte da carga comunicativa que tem, já que se torna objeto de ensino/aprendizagem. Com isso, observamos que o trabalho com a redação (entendida como um texto inerte), com a produção textual (concebida como um texto produzido em uma situação comunicativa) e com o gênero textual (entendido como um enunciado produzido em práticas sociais de letramento, envolvendo um tema, uma composição e um registro lingüístico) tem um ponto comum, que é ser objeto de ensino. E para isso, é necessário um planejamento de atividades, incluindo ou plano de aula ou modelo didático, de forma que o professor não se desfaça dessa característica de objeto de ensino, a ponto de não mais ensinar a produzir um texto em sala de aula, sob o pretexto de que o importante é respeitar as práticas sociais da escrita e seus usos. Permanecer falando sobre o texto escrito, sem efetivamente pôr em prática seu ensino, faz com que o professor não realize sua atividade didática. 


\section{Referências}

BEZERRA, Ma. Auxiliadora. From Composition to Genres: a brief history of the teaching of the written text in Brazilian schools. Revista da ANPOLL, Campinas, n.20, p.103-129, Jan./ Jun, 2006.

DE PIETRO, J.-F \& SCHNEUWLY, B. Le modèle didactique du genre : un concept de l'ingénierie didactique. Bulletin de THEODILE, n.2, p. 45-67, 2002.

DOLZ, J.; B. SCNEUWLY \& J.-F. DE PIETRO. Récit d'élaboration d'une séquence: le débat publique. In: Pour un enseignement de l'oral: iniciation aux genres formels à l'école. Paris: ESF Éditeurs, 1998.

GIL, Antônio C. Metodologia do ensino superior. São Paulo: Atlas, 1997.

LIBÂNEO, José C. Organização e gestão escolar. Goiânia: Alternativa, 2004.

MATENCIO, Ma. de Lourdes. Estudo da língua falada e aula de língua materna. Campinas: Mercado de Letras, 2001.

ROJO, Roxane H. R. Modelização didática e planejamento: duas práticas esquecidas do professor? In: KLEIMAN, A. (org.). A formação do professor: Campinas: Mercado de Letras, p.313335, 2001.

VYGOTSKY, Lev. A formação social da mente. São Paulo: Martins Fontes, 1984. 